\title{
Interactive Effects of Moss-Dominated Crusts and Artemisia ordosica on Wind Erosion and Soil Moisture in Mu Us Sandland, China
}

\author{
Yongsheng Yang, ${ }^{1}$ Chongfeng Bu, ${ }^{1,2}$ Xingmin Mu, ${ }^{1,2}$ Hongbo Shao, ${ }^{1,3}$ and Kankan Zhang ${ }^{2}$ \\ ${ }^{1}$ State Key Laboratory of Soil Erosion and Dryland Farming of the Loess Plateau, Institute of Soil and Water Conservation, \\ Chinese Academy of Sciences and Ministry of Water Resources, Yangling, Shaanxi 712100, China \\ ${ }^{2}$ Institute of Soil and Water Conservation, Northwest A\&F University, Yangling, Shaanxi 712100, China \\ ${ }^{3}$ Key Laboratory of Coastal Biology \& Bioresources Utilization, Yantai Institute of Coastal Zone Research (YIC), \\ Chinese Academy of Sciences (CAS), Yantai 264003, China \\ Correspondence should be addressed to Chongfeng Bu; buchongfeng@163.com and Xingmin Mu; xmmu@ms.iswc.ac.cn
}

Received 23 April 2014; Revised 14 May 2014; Accepted 15 May 2014; Published 1 June 2014

Academic Editor: Xu Gang

Copyright (C) 2014 Yongsheng Yang et al. This is an open access article distributed under the Creative Commons Attribution License, which permits unrestricted use, distribution, and reproduction in any medium, provided the original work is properly cited.

To better understand the effects of biological soil crusts (BSCs) on soil moisture and wind erosion and study the necessity and feasibility of disturbance of BSCs in the Mu Us sandland, the effects of four treatments, including moss-dominated crusts alone, Artemisia ordosica alone, bare sand, and Artemisia ordosica combined with moss-dominated crusts, on rainwater infiltration, soil moisture, and annual wind erosion were observed. The major results are as follows. (1) The development of moss-dominated crusts exacerbated soil moisture consumption and had negative effects on soil moisture in the Mu Us sandland. (2) Moss-dominated crusts significantly increased soil resistance to wind erosion, and when combined with Artemisia ordosica, this effect became more significant. The contribution of moss-dominated crusts under Artemisia ordosica was significantly lower than that of mossdominated crusts alone in sites where vegetative coverage $>50 \%$. (3) Finally, an appropriate disturbance of moss-dominated crusts in the rainy season in sites with high vegetative coverage improved soil water environment and vegetation succession, but disturbance in sites with little or no vegetative cover should be prohibited to avoid the exacerbation of wind erosion.

\section{Introduction}

Biological soil crusts (BSCs) are complex assemblages of phylogenetically and functionally diverse organisms such as macroscopic bryophytes (e.g., mosses and liverworts), lichens, microscopic archaea, bacteria, cyanobacteria, microfungi, and green algae $[1,2]$. The biotic components of BSCs have a high tolerance for low moisture, extreme temperatures, and light and are therefore widely distributed in regions characterized by periodic dryness, intense heat, and strong light, which constitute over $35 \%$ of the world's terrestrial land $[3,4]$. BSCs perform several functions in arid and semiarid ecosystems. For example, many studies have demonstrated that BSCs have a significant influence on rainwater infiltration [5], runoff [4], and evaporation [6] in arid and semiarid regions. Furthermore, BSCs prevent soil erosion by water
[7] or wind [8], increase the possibility of vascular plant colonization [9], stabilize soil surface [10], and fix carbon on sparsely vegetated areas in arid regions [11]. In other words, BSCs are critical structural and functional components of arid and semiarid ecosystems.

In China, the desertification occurring in arid and semiarid regions threatens approximately $3.3 \times 10^{6} \mathrm{~km}^{2}$ of land, which is inhabited by 400 million people [12]. As the main indicator of dune stabilization, BSCs have been widely distributed in arid and semiarid regions. In Mu Us sandland, BSCs have widely developed in enclosed regions and have already deeply affected soil moisture and vegetation succession [13]. However, most literatures on BSCs, hydrology, or wind erosion in China have focused mainly on ariddesert regions, such as the Tengger Desert, Kubuqi Desert, and Gurbantünggüt Desert. Little attention has been paid 
to the roles of BSCs in soil moisture or wind erosion in the $\mathrm{Mu}$ Us sandland, where the annual average rainfall is approximately $400 \mathrm{~mm}$ [14]. Therefore, studying the effects of BSCs on soil moisture and wind erosion in Mu Us sandland could contribute to a more complete understanding of the ecological function of BSCs.

Several previous studies have investigated the function of BSCs on water dynamics, but the results have not been consistent due to the complex process of interception by BSCs. For example, BSCs have been found to enhance [5, 15] or reduce [16] water infiltration and to increase [17] or decrease [14] the occurrence of runoff, while other studies have shown that BSCs have no effect on infiltration [18]. In opposition to these studies, other studies report that BSCs increased the soil threshold friction velocities, which are required to detach particles from the soil surfaces [11] and drastically decrease wind erosion [19]. However, BSCs are easily damaged by disturbance, such as livestock, human traffic, sand burial, and animal burrowing due to their weak structural attributes [16]. Artemisia ordosica is one of the dominant shrubs in the Mu Us sandland [20], and BSCs often grow under it. Researchers generally agree that shrubs with dense branches (e.g., Artemisia ordosica) protect soil from wind erosion [21]. At present, many researchers are studying the effects of Artemisia ordosica alone and moss-dominated crusts alone on wind erosion and soil moisture [11, 21, 22], respectively, but less attention has been paid to the interactive effects of BSCs and Artemisia ordosica on these processes. Thus, we hypothesize that moss-dominated crusts in the $\mathrm{Mu}$ Us sandland could reduce the infiltration depths of rainwater and decrease soil moisture in the deep layer and that the ability of moss-dominated crusts under Artemisia ordosica to resist wind erosion is significantly lower than that of moss-dominated crusts alone. If true, moderate disturbance to moss-dominated crusts under vegetation could improve soil moisture while maintaining wind erosion control. These actions would positively benefit ecological restoration in arid and semiarid regions.

The objectives of this research are as follows: (1) to quantify the effects of moss-dominated crusts on soil moisture and wind erosion, and (2) to study the interactive effects of moss-dominated crusts and Artemisia ordosica in the $\mathrm{Mu}$ Us sandland on soil moisture and wind erosion. Based on these analyses, we discuss the necessity and feasibility of disturbance on moss-dominated crusts in semiarid regions.

\section{Materials and Methods}

2.1. Experiment Site. A field experiment was conducted in Gechougou located in Shenmu County Shaanxi province $\left(38^{\circ} 10^{\prime}-39^{\circ} 05^{\prime} \mathrm{N}\right.$ latitude, $109^{\circ} 40^{\prime}-110^{\circ} 30^{\prime} \mathrm{E}$ longitude), China. The average annual temperature in this region is $7.8^{\circ} \mathrm{C}$, and the average temperatures of the hottest month (July) and the coldest month (January) are $23.9^{\circ} \mathrm{C}$ and $-9.8^{\circ} \mathrm{C}$, respectively. The prevailing wind is from the northwest, and the annual average wind speed is $3.2 \mathrm{~m} \cdot \mathrm{s}^{-1}$, with a maximum wind speed of $24 \mathrm{~m} \cdot \mathrm{s}^{-1}$ and more than 200 days per year having a wind speed greater than $5 \mathrm{~m} \cdot \mathrm{s}^{-1}$ [23]. The average annual rainfall and evaporation are $440.8 \mathrm{~mm}$ and $2090 \mathrm{~mm}$, respectively. The dominant soil type is aeolian sandy soil and the landscape is characterized by mobile and semifixed sand dunes. The major vegetation consists of drought-tolerant, short shrubs and grasses, including Artemisia ordosica, Salsola passerina, and Caragana microphylla [20]. The annual mean hours of sunshine are 2800-3100 hours, and the annual total solar radiation is $138-150 \mathrm{kcal} \mathrm{cm}^{-2}$ [24]. The groundwater level is low and small lakes called "Haizi" are widely distributed in this region. BSCs in the experiment site are dominated by moss, while algae are less prevalent. The species of BSCs that have been identified are Bryum pallescens, Bryum recurvulum Mitt, Bryum argenteum, and Barbula unguiculata Hedw. The Mu Us sandland is the largest mobile dune system of the dry and nutrient-poor grasslands in northwestern of China, where desertification is becoming problematic [25].

\subsection{Method}

2.2.1. Experimental Design. In mid-April 2008, eight experimental plots were established on a $15^{\circ}$ slope. Each plot was $4 \mathrm{~m} \times 2 \mathrm{~m}$ in size and oriented from south to west. Artemisia ordosica was planted in four plots in May 2008, and seedlings were thinned into a rectangular shape $(30 \mathrm{~cm} \times$ $50 \mathrm{~cm}$ ) after the seeds germinated. Four separate plots were created with bare sand. In July 2008, well-developed mossdominated crusts from another research site were carefully translocated to the soil surface of two bare sand plots and two Artemisia ordosica plots. The experiment included four treatments: moss-dominated crusts (MDCs) alone, Artemisia ordosica (AO) alone, bare sand (BS), and Artemisia ordosica combined with moss-dominated crusts (AO + MDCs). Each treatment had two replicates (Figure 1). Fiberglass access tubes (inner diameter: $40 \mathrm{~mm}$; length: $250 \mathrm{~cm}$ ) were installed in the middle of each plot. Weeds were cleaned regularly and well managed.

In October 2010, the vegetative cover and BSCs were 50\% and $95 \%$, respectively. The thickness of crusts measured using a Vernier caliper was $1.61 \pm 0.10 \mathrm{~cm}$ (means $\pm \mathrm{SE}, n=12)$. The soil particle size distribution at $0-2 \mathrm{~cm}$ of BS and MDCs was measured by Mastersizer 2000E (Malvern Instruments Ltd. Worcestershire, UK) [26], shown in Table 1.

2.2.2. Soil Moisture and Wind Erosion Measurement. Soil moisture monitoring was conducted from April to September in 2011 (in the fourth year after layout). The soil moisture content at $0-16 \mathrm{~cm}$ was collected using a Probe-TDR (TRIMEIPH) (IMKO, Ettlingen, Germany), and the soil moisture content at $20-240 \mathrm{~cm}$ (at $10 \mathrm{~cm}$ intervals from 20 to $100 \mathrm{~cm}$ and $20 \mathrm{~cm}$ intervals from 100 to $240 \mathrm{~cm}$ ) was collected at each plot using a Tube-TDR [27]. The soil moisture content was measured three times from April to May and eight times from July to September. Soil moisture was collected 24 hours before and after rainfall events, according to the weather forecasts. Rainfall data during the experiment were collected using a tipping-bucket rain gauge (Figure 2). 


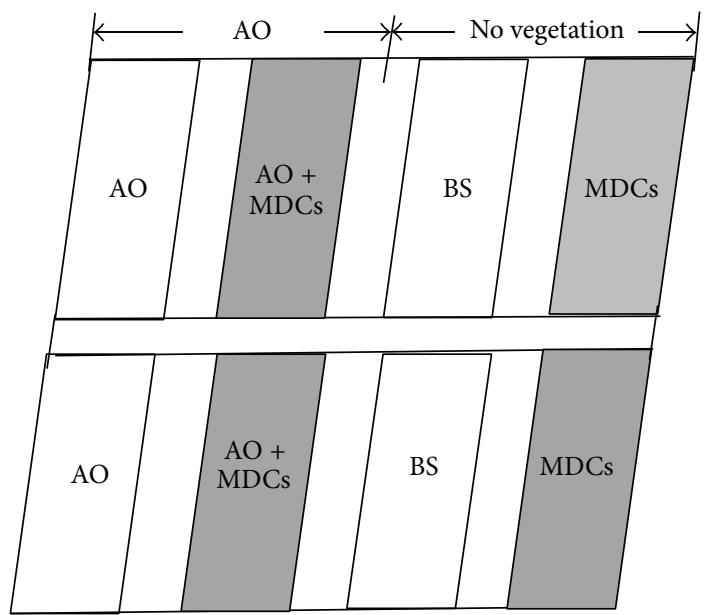

MDCs

No crusts

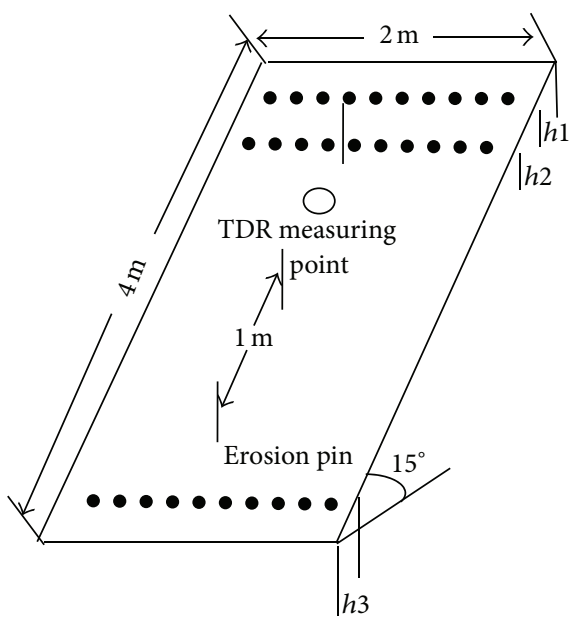

$\mathrm{AO}$

$h 1$ : distance from the first line to the top, $30 \mathrm{~cm}$ $h 2$ : line spacing, $50 \mathrm{~cm}$

$h 3$ : distance from the last line to the bottom, $20 \mathrm{~cm}$

(a)

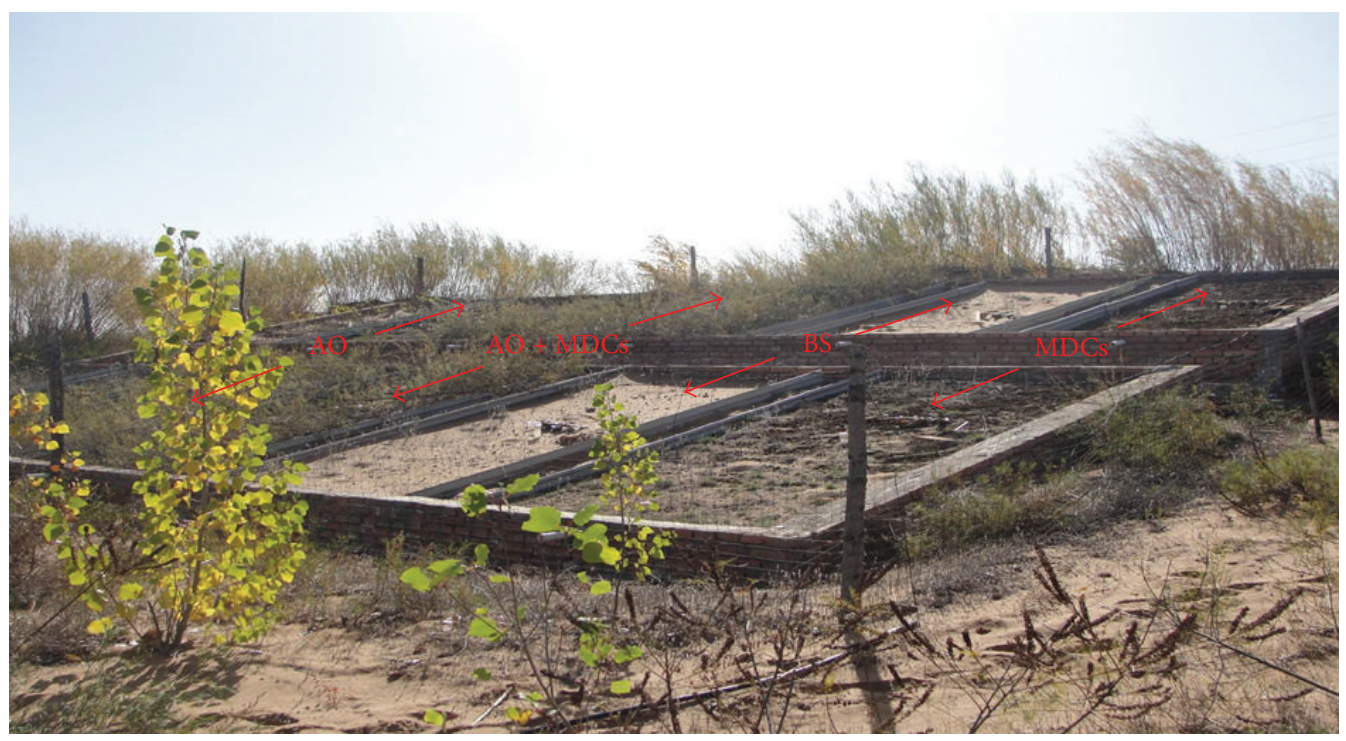

(b)

FIGURE 1: Sketch map (a) and photograph (b) of the 8 plots.

TABLE 1: Soil particle size of the top layer $(0-2 \mathrm{~cm})$ in bare sand (BS) and moss-dominated crusts (MDCs).

\begin{tabular}{lcccc}
\hline & $<0.002 \mathrm{~mm}$ & $0.002-0.02 \mathrm{~mm}$ & $0.02-0.2 \mathrm{~mm}$ & $0.2-2 \mathrm{~mm}$ \\
\hline MDCs & $0.7 \%$ & $2.0 \%$ & $35.1 \%$ & $62.2 \%$ \\
BS & $0.3 \%$ & $1.1 \%$ & $12.5 \%$ & $86.1 \%$ \\
\hline
\end{tabular}

In October 2010, the erosion pins, which were $50 \mathrm{~cm}$ (30 cm above soil surface) in height, were inserted at upper, middle, and lower sites of each plot (Figure 1), with the notch of the erosion pin flush with the soil surface. The height from the notch on the erosion pin to the soil surface in October
2011 was measured. The annual wind erosion was calculated using the following equation [28]:

$$
Q=\frac{H \times 1.5 \times 10^{-6}}{10^{-8}},
$$

where $Q$ is the annual wind erosion in $\mathrm{t} / \mathrm{ha} / \mathrm{a}, H$ is the change in height between notches on the erosion pin and soil surface in one year in $\mathrm{cm} / \mathrm{a}, 1.5$ is the bulk density of soil in $\mathrm{g} / \mathrm{cm}^{3}$ [28], $10^{-6}$ is the conversion between gram and ton, and $10^{-8}$ is the conversion between square centimeter and hectare.

2.3. Statistical Analysis. Data were expressed as the means \pm standard error. Significant differences among 


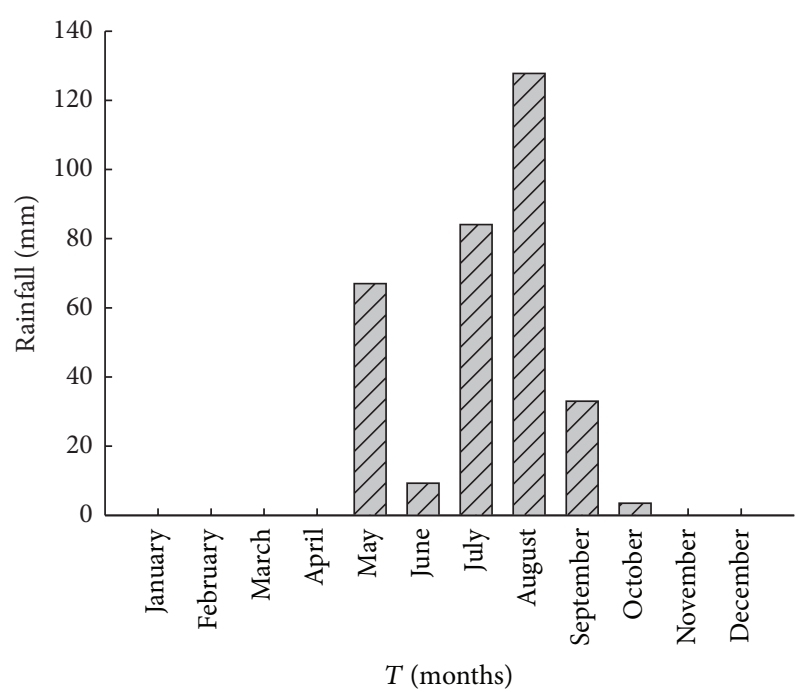

FIGURE 2: Monthly rainfall in the study region in 2011.

different treatments were tested by one-way ANOVA and LSD using SPSS 12.0 (SPSS Inc., Chicago, IL, USA). Significance was set at $P<0.05$.

\section{Results}

3.1. Effects of Moss-Dominated Crusts on Infiltration. The variation in soil water-storage and the total infiltration at different soil depths for the four plots after an $8.3 \mathrm{~mm}$ rain event are shown in Figures 3 and 4, respectively. The results indicated that the infiltration depths of MDCs alone and $\mathrm{AO}+\mathrm{MDCs}$ were all lower than those of $\mathrm{AO}$ alone and the BS plots (Figure 3). For the total infiltration (sum of increased soil moisture), there was no significant difference among the four plots (Figure 4). These results indicate that when the daily rainfall is $8.3 \mathrm{~mm}$, the existence of MDCs reduces the infiltration depth of rainwater and retains rainwater in shallower soil.

\subsection{Effects of Moss-Dominated Crusts on Profile Distribution} of Soil Moisture. The profiles of the distribution of soil moisture from $0 \mathrm{~cm}$ to $240 \mathrm{~cm}$ in the dry (April to May) and rainy (July to September) seasons in each plot are shown in Figures 5 and 6 . In both the dry and rainy seasons, most of the soil moisture content observed for the four plots was below $12 \%$.

In the dry season (Figure 5(a)), the soil moisture content in depths above $200 \mathrm{~cm}$ in the MDCs alone plots was lower than the content in the BS plots, while an opposite trend was observed in depths below $200 \mathrm{~cm}$. In the rainy season (Figure 6(a)), the effects of MDCs on soil moisture were similar to those observed in the dry season, except the soil moisture content at a depth of $0-16 \mathrm{~cm}$ in the MDCs alone plots was higher than that in the BS plots. These results suggest that the presence of moss-dominated crusts alone could retain the rainwater in shallow soil during the rainy season.

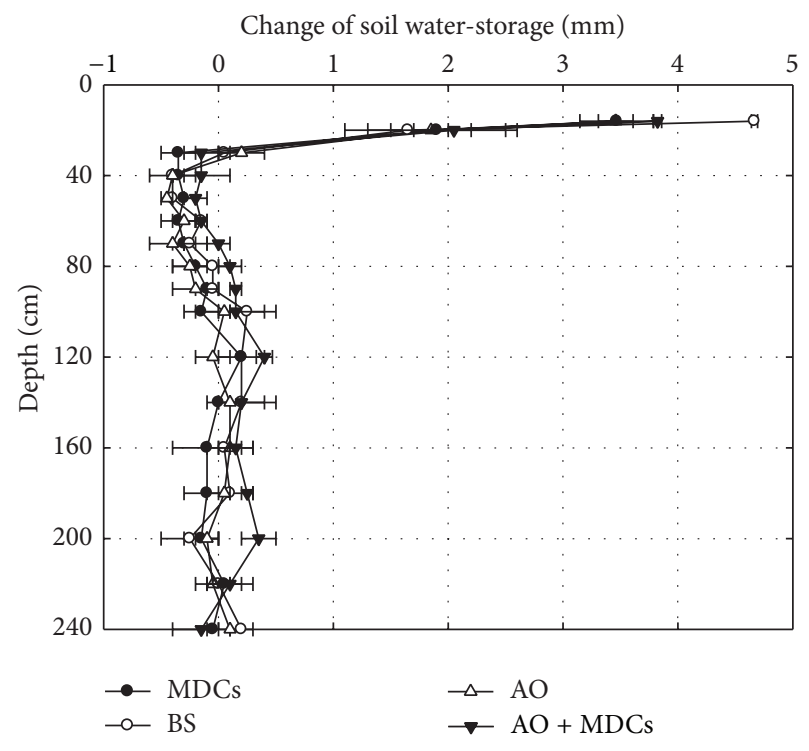

FIGURE 3: Change in soil water-storage of moss-dominated crusts plots (MDCs), bare sand plots (BS), Artemisia ordosica plots (AO), and Artemisia ordosica combined with moss-dominated crusts plots (AO + MDCs) after an $8.3 \mathrm{~mm}$ rain event.

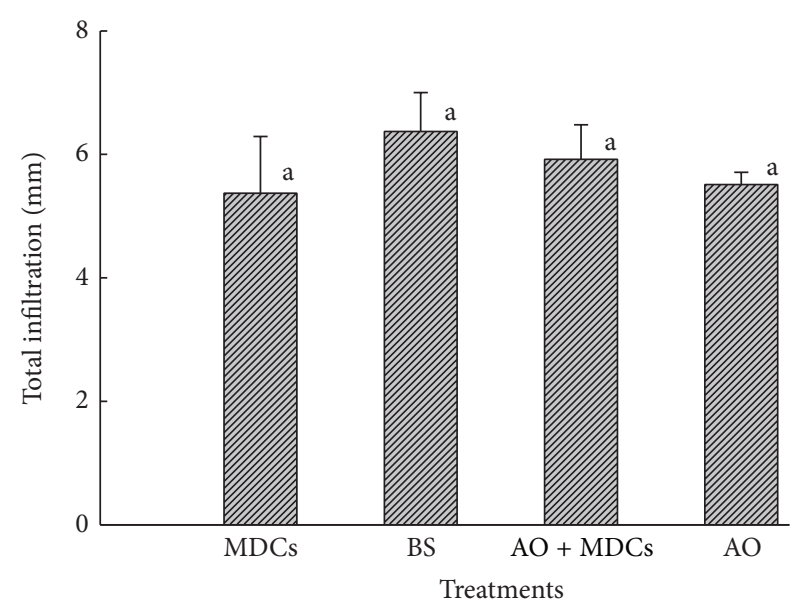

Figure 4: Total infiltration of the moss-dominated crusts plots (MDCs), bare sand plots (BS), Artemisia ordosica plots (AO), and Artemisia ordosica combined with moss-dominated crusts plots $(\mathrm{AO}+\mathrm{MDCs})$ after an $8.3 \mathrm{~mm}$ rain event. Note: different letters indicate significant differences at a $5 \%$ probability level.

Figure 5(b) shows that the soil moisture contents in the depth ranges of $0-50 \mathrm{~cm}$ and $100-140 \mathrm{~cm}$ in the $\mathrm{AO}$ alone plots were lower than those in the BS plots and that the soil moisture content from 0 to $70 \mathrm{~cm}$ in the $\mathrm{AO}$ alone plots was lower than that in the BS plots in the rainy season (Figure 6(b)). However, in both the dry and rainy seasons, the soil moisture content from 0 to $120 \mathrm{~cm}$ in AO + MDCs plots was always lower than that in the BS plots. Meanwhile, compared with the $\mathrm{AO}$ alone plots, the average soil moisture content from 0 to $240 \mathrm{~cm}$ in the $\mathrm{AO}+\mathrm{MDCs}$ plots decreased by $5.7 \%$ and $7.5 \%$ in both the dry and rainy seasons. These results suggest that the development of MDCs under $\mathrm{AO}$ not 


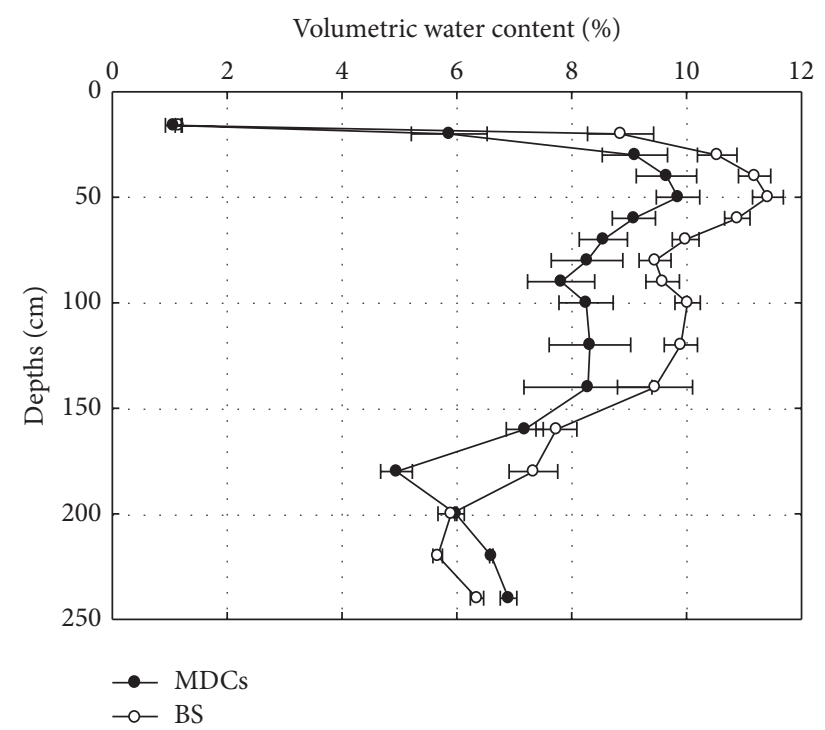

(a)

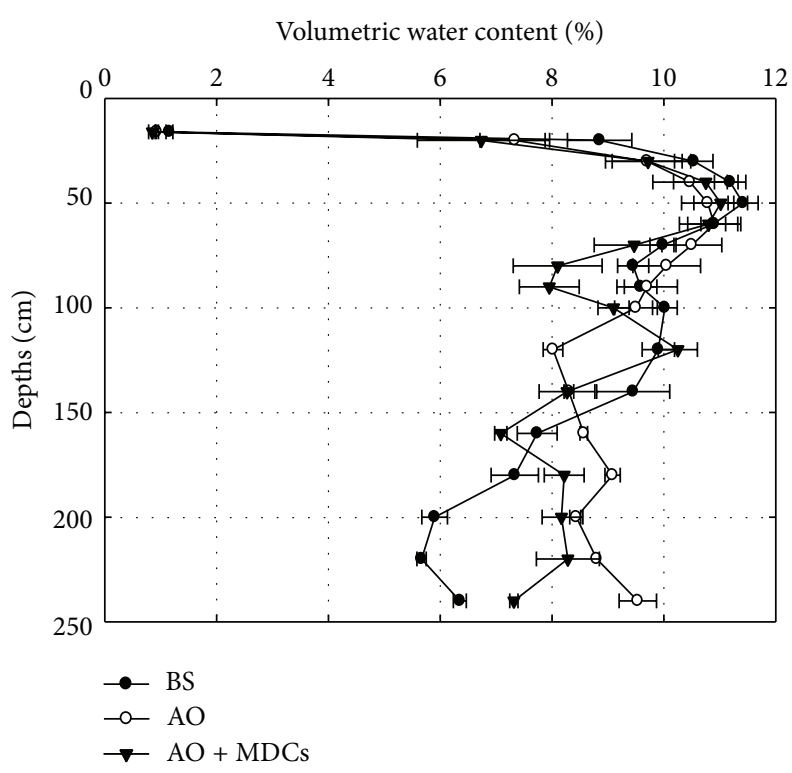

(b)

Figure 5: Volumetric water content from $10 \mathrm{~cm}$ to $240 \mathrm{~cm}$ of bare sand plots (BS), moss-dominated crusts plots (MDCs), Artemisia ordosica plots (AO), and Artemisia ordosica combined with moss-dominated crusts plots (AO + MDCs) in the dry season (April to May).

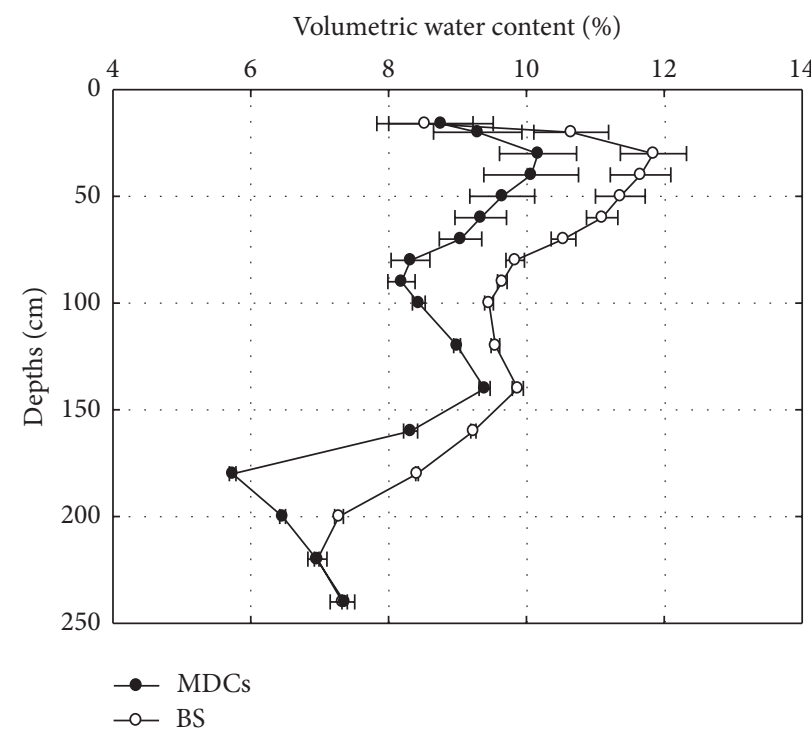

(a)

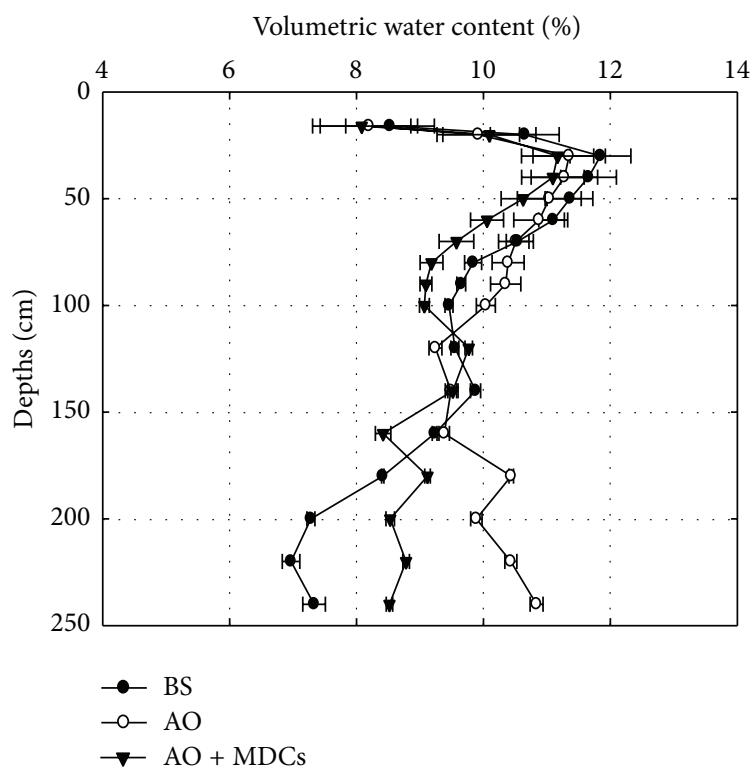

(b)

FIGURE 6: Volumetric water content from $10 \mathrm{~cm}$ to $240 \mathrm{~cm}$ of bare sand plots (BS), moss-dominated crusts plots (MDCs), Artemisia ordosica plots (AO), and Artemisia ordosica combined with moss-dominated crusts plots (AO + MDCs) in the rainy season (July to September).

only increased the depth of soil moisture consumption but also led to greater losses of soil moisture.

The average soil moisture content at different depths, the efficiency of reducing the soil moisture content at depth of $0-160 \mathrm{~cm}(160 \mathrm{~cm}$ is the length of a three-year-old AO root [29]), and the contributions of MDCs to decreasing soil moisture following the different treatments during the dry and rainy seasons are listed in Tables 2 and 3, respectively.
The results showed the following: (1) regardless of whether the plot had AO coverage, MDCs had no significant effects on soil moisture content from 0 to $16 \mathrm{~cm}(P>0.05)$; (2) during both the dry (Table 2) and rainy (Table 3 ) seasons, the efficiency of reducing soil moisture content from 0 to $160 \mathrm{~cm}$ in each plot was found to decrease in the following order: MDCs alone $>\mathrm{AO}+\mathrm{MDCs}>\mathrm{AO}$ alone, and the difference between the soil moisture content in each treatment was statistically 
TABLE 2: Average soil water content of moss-dominated crusts alone plots (MDCs), bare sand plots (BS), Artemisia ordosica alone plots (AO), and Artemisia ordosica combined with moss-dominated crusts plots (AO + MDCs) at different depths in the dry season.

\begin{tabular}{lcccc}
\hline Treatment plot & MDCs & BS & AO + MDCs & AO \\
\hline $0-16 \mathrm{~cm}$ & $1.1 \pm 0.1^{\mathrm{ab}}$ & $1.2 \pm 0.1^{\mathrm{a}}$ & $0.9 \pm 0.1^{\mathrm{b}}$ & $0.9 \pm 0.0^{\mathrm{ab}}$ \\
$20-40 \mathrm{~cm}$ & $8.2 \pm 0.6^{\mathrm{a}}$ & $10.2 \pm 0.4^{\mathrm{a}}$ & $9.1 \pm 0.8^{\mathrm{a}}$ & $9.2 \pm 0.6^{\mathrm{a}}$ \\
$40-160 \mathrm{~cm}$ & $8.4 \pm 0.5^{\mathrm{a}}$ & $9.8 \pm 0.3^{\mathrm{b}}$ & $9.1 \pm 0.4^{\mathrm{ab}}$ & $9.6 \pm 0.3^{\mathrm{b}}$ \\
$160-240 \mathrm{~cm}$ & $6.1 \pm 0.1^{\mathrm{b}}$ & $6.3 \pm 0.1^{\mathrm{bc}}$ & $8.0 \pm 0.3^{\mathrm{d}}$ & $9.0 \pm 0.1^{\mathrm{a}}$ \\
$0-160 \mathrm{~cm} \mathrm{ASW} \mathrm{( \% )}$ & $7.8 \pm 0.2^{\mathrm{b}}$ & $9.2 \pm 0.2^{\mathrm{c}}$ & $8.5 \pm 0.2^{\mathrm{ab}}$ & $8.8 \pm 0.2^{\mathrm{ac}}$ \\
$0-160 \mathrm{~cm}$ ERS (\%) & $15.7 \pm 1.3^{\mathrm{a}}$ & $0.0^{\mathrm{b}}$ & $8.4 \pm 0.5^{\mathrm{c}}$ & $3.5 \pm 1.6^{\mathrm{d}}$ \\
$0-160 \mathrm{~cm} \mathrm{CBR} \mathrm{( \% )}$ & $15.7 \pm 1.3^{\mathrm{a}}$ & & $3.4^{\mathrm{b}}$ & \\
\hline
\end{tabular}

Note: different letters in the same column indicate significant differences at $5 \%$ probability level.

Average soil moisture content, ASW.

Efficiency of reducing soil moisture content $=(1-$ soil moisture content in current treatment $/$ soil moisture content in BS $) \times 100$, ERS.

Contribution of MDCs to reducing soil moisture content $=((1-$ soil moisture content in current treatment with MDCs/soil moisture content in BS $)-(1-$ soil moisture content in current treatment without MDCs/soil moisture content in BS)) $\times 100, \mathrm{CBR}$.

TABLE 3: The average soil water content of moss-dominated crusts alone plots (MDCs), bare sand plots (BS), Artemisia ordosica alone plots (AO), and Artemisia ordosica combined with moss-dominated crusts plots ( $\mathrm{AO}+\mathrm{MDCs})$ at different depths in the rainy season.

\begin{tabular}{lcccc}
\hline Treatment plot & MDCs & BS & AO + MDCs & AO \\
\hline $0-16 \mathrm{~cm}$ & $8.8 \pm 0.8^{\mathrm{a}}$ & $8.5 \pm 0.7^{\mathrm{a}}$ & $8.1 \pm 0.8^{\mathrm{a}}$ & $8^{\mathrm{a}} \pm 0.8^{\mathrm{a}}$ \\
$20-40 \mathrm{~cm}$ & $9.8 \pm 0.5^{\mathrm{a}}$ & $11.4 \pm 0.4^{\mathrm{b}}$ & $10.8 \pm 0.5^{\mathrm{ab}}$ & $10.9 \pm 0.5^{\mathrm{ab}}$ \\
$40-160 \mathrm{~cm}$ & $8.9 \pm 0.2^{\mathrm{a}}$ & $7.1 \pm 0.1^{\mathrm{b}}$ & $9.5 \pm 0.1^{\mathrm{c}}$ & $10.2 \pm 0.1^{\mathrm{bd}}$ \\
$160-240 \mathrm{~cm}$ & $6.6 \pm 0.0^{\mathrm{a}}$ & $10.3 \pm 0.1^{\mathrm{b}}$ & $8.7 \pm 0.0^{\mathrm{c}}$ & $10.4 \pm 0.1^{\mathrm{d}}$ \\
$0-160 \mathrm{~cm} \mathrm{ASW} \mathrm{( \% )}$ & $9.1 \pm 0.2^{\mathrm{a}}$ & $0.0^{\mathrm{b}}$ & $9.7 \pm 0.2^{\mathrm{c}}$ & $10.2 \pm 0.2^{\mathrm{b}}$ \\
$0-160 \mathrm{~cm}$ ERS (\%) & $11.5 \pm 1.0^{\mathrm{a}}$ & & $5.7 \pm 0.4^{\mathrm{c}}$ & \\
$0-160 \mathrm{~cm} \mathrm{CBR} \mathrm{( \% )}$ & $11.5 \pm 1.0^{\mathrm{a}}$ & $4.7 \pm 0.4^{\mathrm{b}}$ & \\
\hline
\end{tabular}

Note: different letters in the same column indicate significant differences at 5\% probability level.

Average soil moisture content, ASW.

Efficiency of reducing soil moisture content $=(1-$ soil moisture content in current treatment/soil moisture content in BS $) \times 100$, ERS .

Contribution of MDCs to reducing soil moisture content $=((1-$ soil moisture content in current treatment with MDCs/soil moisture content in BS $)-(1-$ soil moisture content in current treatment without MDCs/soil moisture content in BS) $) \times 100$, CBR.

significant $(P<0.05)$; and $(3)$ the average soil moisture content in the deep layer $(160-240 \mathrm{~cm})$ of the AO alone plots increased by $11.1 \%$ and $16.3 \%$ compared with that of the AO + MDCs plots in the dry and rainy seasons, respectively. The difference between the treatments was significant $(P<0.05)$. To distinguish the contributions of MDCs from those of MDCs planted with $\mathrm{AO}$ on the reduction of soil moisture, the contribution of MDCs to reduction of soil moisture content was analyzed further. The analysis showed that compared with the BS plots, the AO + MDCs plots decreased the soil moisture from 0 to $160 \mathrm{~cm}$ depth in the dry and rainy seasons by $8.4 \%$ and $5.7 \%$, respectively, and the proportional contribution of MDCs was $46.4 \%$ and $82.5 \%$, respectively.

3.3. Effects of Moss-Dominated Crusts on Wind Erosion. The annual wind erosion of each plot in 2011 is listed in Table 4. The presence of MDCs or AO significantly reduced wind erosion $(P<0.05)$. The contributions of the different treatments to reduce annual wind erosion were found to decrease in the following order: $\mathrm{AO}+\mathrm{MDCs}>\mathrm{MDC}$ alone $>$ $\mathrm{AO}$ alone. It is worth noting that MDCs alone reduced wind erosion by up to $90.6 \%$, but the contribution of MDCs to the reduction of wind erosion dramatically dropped to 21.3\% when combined with AO. These results indicate that an appropriate disturbance of MDCs could prevent drastic increases in wind erosion in those sites where vegetation coverage has reached a relatively high degree $(>50 \%)$. This conclusion is similar to that found in the Tengger Desert [30].

\section{Discussion and Conclusion}

4.1. How Do Moss-Dominated Crusts Affect Soil Moisture? Soil moisture plays an important role in soil nutrient cycling, soil temperature, and vegetation distribution [31-34]. The results of our study showed that moss-dominated crusts reduced the water infiltration depths and retained rainwater in shallow soils and these results were similar to those found in previous studies [16, 22]. This phenomenon could be explained by three factors: (1) BSCs in the Mu Us sandland were not water repellent and they can absorb a large amount of water [14]; (2) the formation of BSCs on the surface of sand dunes caused a decrease in soil particle size [35], and the water-holding capacity of subsurface soil was largely enhanced [36]; (3) during rainfall events, dust that had fallen on the crusts and swelled microbial exudates (e.g., extracellular polymeric substances) sealed the matrix porosity of BSCs $[37,38]$ and prolonged the time that water remained on the surface of BSCs [14]. A study in the Tengger Desert found 
TABLE 4: Annual wind erosion of moss-dominated crusts alone plots (MDCs), bare sand plots (BS), Artemisia ordosica alone plots (AO), and Artemisia ordosica combined with moss-dominated crusts plots (AO + MDCs) in 2011.

\begin{tabular}{lccc}
\hline Treatment plot & $\begin{array}{c}\text { Annual wind erosion } \\
\left(\mathrm{t} \cdot \mathrm{ha}^{-1} \cdot \mathrm{a}^{-1}\right)\end{array}$ & Efficiency of reducing wind erosion (\%) & $\begin{array}{c}\text { Contribution of MDCs to reducing } \\
\text { annual wind erosion }(\%)\end{array}$ \\
\hline MDCs & $51.5 \pm 7.0^{\mathrm{bc}}$ & $90.6 \pm 3.2^{\mathrm{a}}$ & $90.6 \pm 3.2^{\mathrm{a}}$ \\
BS & $592.5 \pm 132.5^{\mathrm{a}}$ & $0.0^{\mathrm{c}}$ & $21.3 \pm 7.5^{\mathrm{b}}$ \\
AO + MDCs & $18.5 \pm 10.0^{\mathrm{b}}$ & $96.3 \pm 2.5^{\mathrm{a}}$ & $75.0 \pm 10.0^{\mathrm{b}}$ \\
AO & $135 \pm 26.0^{\mathrm{c}}$ & & \\
\hline
\end{tabular}

Note: different letters in the same column indicate significant differences at $5 \%$ probability level.

Efficiency of reducing wind erosion $=(1-$ annual wind erosion in current treatment/annual wind erosion in BS $) \times 100$.

Contribution of MDCs to reducing wind erosion $=((1-$ annual wind erosion in current treatment with MDCs/BS $)-(1-$ annual wind erosion in current treatment without MDCs/BS)) $\times 100$.

that BSCs reduced the rainwater infiltration depths when the daily rainfall was below $10 \mathrm{~mm}$ [39], which is supported by the results presented in this study. Based on the long-term monitoring of rainfall in the Mu Us sandland, researchers found that $84.6 \%$ of the daily rainfall over the entire year was less than $10 \mathrm{~mm}$ for this region [13]. Thus, moss-dominated crusts in the $\mathrm{Mu}$ Us sandland could reduce the infiltration depths of most rainfall events and retain rainwater in shallow soil. However, crusts resulted in a greater total water loss through evaporation under abundant precipitation (high soil moisture) $[40,41]$. Soil moisture that was retained in shallow soil could be evaporated quickly. At the end of the rainy season, the soil moisture in soil covered by moss-dominated crusts was lower than that in bare sand. Therefore, in the long run, moss-dominated crusts in the $\mathrm{Mu}$ Us sandland have negative effects on soil moisture and are harmful for the succession of deep-rooted plants.

4.2. Necessity and Feasibility of Disturbance of MossDominated Crusts. Previous research indicates that BSCs play a positive role in the initial stage of their growth, such as improving the characteristics of soil's physical structure and chemical properties [42], enriching shallow soil [43], and promoting the germination and colonization of herbaceous plants [44]. However, there was an opposite trend in the later period of BSCs development. First, thick and hard moss-dominated crusts act as a "coat" and prevent the seeds of perennial plants from penetrating into the soil $[45,46]$, reduce the number of juvenile plants, and cause imbalances in the age-class distribution of plant populations. Second, the growth of moss-dominated crusts increased the loss of soil moisture and significantly reduced soil moisture in deeper soil. Therefore, the further development of moss-dominated crusts is harmful for the normal succession of deep-root vegetation and has negative effects on the recovery process of degraded ecosystem in arid and semiarid regions.

Our findings suggest that when the vegetative cover has reached a relatively high degree $(>50 \%)$, a disturbance of moss-dominated crusts will not drastically increase wind erosion. Research in the Tengger Desert has shown that the disturbance of moss-dominated crusts increases the amount and depth of rainfall infiltration [17] and decreases the evaporation rate [16], which is of great benefit to improving the soil moisture in arid and semiarid regions. The growth period of Artemisia ordosica in the Mu Us sandland begins in mid-March and is most vigorous in July. During this period, wind speeds decreased, while rainfall increased gradually. Thus, we conclude that in sites with high vegetative cover, appropriate disturbance measurements should be conducted on moss-dominated crusts in late April or early May (at the end of the wind season and at the start of the rainy season). In this case, the disturbance of moss-dominated crusts under vegetation can improve soil moisture to some degree, which is of benefit to the growth of the vegetation and will not significantly increase soil erosion. However, in sites with little or no vegetation, moss-dominated crusts primarily function in wind-breaking and sand fixation, and an improper disturbance would greatly increase the occurrence of desertification. Thus, disturbance should be strictly prohibited in these regions. It is necessary to note that we studied the effects of severe disturbance, which completely removed the moss-dominated crusts under vegetation, on soil moisture and wind erosion and that these effects are likely different from the effects of slight or intermediate disturbance. Thus, to comprehensively understand the interactive effects of different disturbance degree on BSCs on soil moisture and wind erosion, more field studies are needed.

\section{Conflict of Interests}

The authors declare that there is no conflict of interests regarding the publication of this paper.

\section{Acknowledgments}

This work was supported by the National Natural Scientific Foundation of China (41071192), the Foundation of State Key Laboratory of Soil Erosion and Dryland Farming on the Loess Plateau (K318009902-1405), and the Chinese Universities Scientific Fund (Grant no. QN2009085). The authors thank the afforestation and desertification base of the Ecological Society of Shenmu County Shaanxi province for supporting and allowing this research.

\section{References}

[1] J. Belnap and O. L. Lange, Biological Soil Crusts: Structure, Function, and Management, Springer, Berlin, Germany, 2001. 
[2] T. Soule, I. J. Anderson, S. L. Johnson, S. T. Bates, and F. GarciaPichel, "Archaeal populations in biological soil crusts from arid lands in North America," Soil Biology and Biochemistry, vol. 41, no. 10, pp. 2069-2074, 2009.

[3] C. Bu, S. Wu, Y. Xie, and X. Zhang, "The study of biological soil crusts: hotspots and prospects," Clean-Soil, Air, Water, vol. 41, no. 9, pp. 899-906, 2013.

[4] J. Belnap, "The potential roles of biological soil crusts in dryland hydrologic cycles," Hydrological Processes, vol. 20, no. 15, pp. 3159-3178, 2006.

[5] S. Chamizo, Y. Cantón, R. Lázaro, A. Solé-Benet, and F. Domingo, "Crust composition and disturbance drive infiltration through biological soil crusts in Semiarid ecosystems," Ecosystems, vol. 15, no. 1, pp. 148-161, 2012.

[6] S. Chamizo, Y. Cantón, F. Domingo, and J. Belnap, "Evaporative losses from soils covered by physical and different types of biological soil crusts," Hydrological Processes, vol. 27, no. 3, pp. 324-332, 2013.

[7] E. Rodríguez-Caballero, Y. Cantón, S. Chamizo, A. Afana, and A. Solé-Benet, "Effects of biological soil crusts on surface roughness and implications for runoff and erosion," Geomorphology, vol. 145-146, no. 1, pp. 81-89, 2012.

[8] Y. M. Zhang, H. L. Wang, X. Q. Wang, W. K. Yang, and D. Y. Zhang, "The microstructure of microbiotic crust and its influence on wind erosion for a sandy soil surface in the Gurbantunggut Desert of Northwestern China," Geoderma, vol. 132, no. 3-4, pp. 441-449, 2006.

[9] C. V. Hawkes, "Effects of biological soil crusts on seed germination of four endangered herbs in a xeric Florida shrubland during drought," Plant Ecology, vol. 170, no. 1, pp. 121-134, 2004.

[10] V. B. Chaudhary, M. A. Bowker, T. E. O'Dell et al., "Untangling the biological contributions to soil stability in semiarid shrublands," Ecological Applications, vol. 19, no. 1, pp. 110-122, 2009.

[11] Y. M. Zhang, H. L. Wang, X. Q. Wang, W. K. Yang, and D. Y. Zhang, "The microstructure of microbiotic crust and its influence on wind erosion for a sandy soil surface in the Gurbantunggut Desert of Northwestern China," Geoderma, vol. 132, no. 3-4, pp. 441-449, 2006.

[12] Y. Zha and J. Gao, "Characteristics of desertification and its rehabilitation in China," Journal of Arid Environments, vol. 37, no. 3, pp. 419-432, 1997.

[13] H. Q. Xiong, J. Y. Duan, Y. Wang et al., "Effects of biological soil crust on water infiltration and redistribution in the Mu Us Sandland, Inner Mongolia, Northern China," Research of Soil and Water Conservation, vol. 18, no. 4, pp. 82-87, 2011, (Chinese with English abstract).

[14] Y. Wu, E. Hasi, and X. Wu, "Characteristics of surface runoff in a sandy area in southern Mu Us sandy land," Chinese Science Bulletin, vol. 57, no. 2-3, pp. 270-275, 2012.

[15] J. Seghieri, S. Galle, J. L. Rajot, and M. Ehrmann, "Relationships between soil moisture and growth of herbaceous plants in a natural vegetation mosaic in Niger," Journal of Arid Environments, vol. 36, no. 1, pp. 87-102, 1997.

[16] S. Z. Li, H. L. Xiao, G. D. Cheng, F. Luo, and L. C. Liu, "Mechanical disturbance of microbiotic crusts affects ecohydrological processes in a region of revegetation-fixed sand dunes," Arid Land Research and Management, vol. 20, no. 1, pp. 61-77, 2006.

[17] X. J. Li, X. R. Li, W. M. Song, Y. P. Gao, J. G. Zheng, and R. L. Jia, "Effects of crust and shrub patches on runoff, sedimentation, and related nutrient $(\mathrm{C}, \mathrm{N})$ redistribution in the desertified steppe zone of the Tengger Desert, Northern China," Geomorphology, vol. 96, no. 1-2, pp. 221-232, 2008.
[18] D. J. Eldridge, M. E. Tozer, and S. Slangen, "Soil hydrology is independent of microphytic crust cover: further evidence from a wooded semiarid australian rangeland," Arid Soil Research and Rehabilitation, vol. 11, no. 2, pp. 113-126, 1997.

[19] J. Belnap and D. A. Gillette, "Vulnerability of desert biological soil crusts to wind erosion: the influences of crust development, soil texture, and disturbance," Journal of Arid Environments, vol. 39, no. 2, pp. 133-142, 1998.

[20] J. Sun, "Origin of eolian sand mobilization during the past 2300 years in the Mu Us Desert, China," Quaternary Research, vol. 53, no. 1, pp. 78-88, 2000.

[21] J. H. Wang, Q. L. Ma, H. J. Liu et al., "Effect of wind-breaking and sand-fixing of vegetation in progressive succession on desertification land in arid area," Journal of Desert Reserch, vol. 26, no. 6, pp. 903-909, 2006, (Chinese with English abstract).

[22] S. Gao, X. Ye, Y. Chu, and M. Dong, "Effects of biological soil crusts on profile distribution of soil water, organic carbon and total nitrogen in Mu Us Sandland, China," Journal of Plant Ecology, vol. 3, no. 4, pp. 279-284, 2010.

[23] B. Wu and L. J. Ci, "Landscape change and desertification development in the Mu Us Sandland, Northern China," Journal of Arid Environments, vol. 50, no. 3, pp. 429-444, 2002.

[24] X. R. Li, "Study on shrub community diversity of Ordos Plateau, Inner Mongolia, Northern China," Journal of Arid Environments, vol. 47, no. 3, pp. 271-279, 2001.

[25] Y. F. Chen, F. H. Yu, and M. Dong, "Scale-dependent spatial heterogeneity of vegetation in Mu Us sandy land, a semi-arid area of China," Plant Ecology, vol. 162, no. 1, pp. 135-142, 2002.

[26] B. Xi, Y. Wang, L. Jia, M. Bloomberg, G. Li, and N. Di, "Characteristics of fine root system and water uptake in a triploid populus tomentosa plantation in the North China Plain: implications for irrigation water management," Agricultural Water Management, vol. 117, pp. 83-92, 2013.

[27] X. Gao, P. Wu, X. Zhao, Y. Shi, J. Wang, and B. Zhang, "Soil moisture variability along transects over a well-developed gully in the Loess Plateau, China," Catena, vol. 87, no. 3, pp. 357-367, 2011.

[28] J. Z. Yang, Priimary Study on Biological Soil Crusts' Effect on Soil Moisture and Artifical Breeding Techniques, Northwest A\&F University, Shaanxi, China, 2010.

[29] J. H. Sun, Study on Root Distribution and Habitat Flexibility of Artemisa Ordosica in Mu Us Sandy Land, Northwest A\&F University, Shaanxi, China, 2008.

[30] J. H. Du, P. Yan, X. L. Zhan, and Y. H. E., "Surface erosionresistance of Nitraria tangutorun nebkhas at different succession stages in Minqin oasis and related affecting factors," Chinese Journal of Applied Ecology, vol. 19, no. 4, pp. 763-768, 2008, (Chinese with English abstract).

[31] L. Xu, H. Niu, J. Xu, and X. Wang, "Nitrate-nitrogen leaching and modeling in intensive agriculture farmland in China," The Scientific World Journal, vol. 2013, Article ID 353086, 10 pages, 2013.

[32] J. S. Famiglietti, J. W. Rudnicki, and M. Rodell, "Variability in surface moisture content along a hillslope transect: Rattlesnake Hill, Texas," Journal of Hydrology, vol. 210, no. 1-4, pp. 259-281, 1998.

[33] R. F. Follett and J. L. Hatfield, "Nitrogen in the environment: sources, problems, and management," TheScientificWorldJournal, vol. 1, pp. 920-926, 2001.

[34] Y. He, S. Yang, J. Xu, Y. Wang, and S. Peng, "Ammonia volatilization losses from paddy fields under controlled irrigation with 
different drainage treatments," The Scientific World Journal, vol. 2014, Article ID 417605, 7 pages, 2014.

[35] X.-R. Li, X.-P. Wang, T. Li, and J.-G. Zhang, "Microbiotic soil crust and its effect on vegetation and habitat on artificially stabilized desert dunes in Tengger Desert, North China," Biology and Fertility of Soils, vol. 35, no. 3, pp. 147-154, 2002.

[36] D. Zhenghu, X. Honglang, L. Xinrong, D. Zhibao, and W. Gang, "Evolution of soil properties on stabilized sands in the Tengger Desert, China," Geomorphology, vol. 59, no. 1-4, pp. 237-246, 2004.

[37] N. N. Barger, J. E. Herrick, J. Van Zee, and J. Belnap, “Impacts of biological soil crust disturbance and composition on $\mathrm{C}$ and $\mathrm{N}$ loss from water erosion," Biogeochemistry, vol. 77, no. 2, pp. 247-263, 2006.

[38] T. Fischer, M. Veste, W. Wiehe, and P. Lange, "Water repellency and pore clogging at early successional stages of microbiotic crusts on inland dunes, Brandenburg, NE Germany," Catena, vol. 80, no. 1, pp. 47-52, 2010.

[39] X. R. Li, Eco-Hydrology of Biological Soil Crusts in Desert Regions of China, High Education Press, Beijing, China, 2011.

[40] L. Liu, Y. Song, Y. Gao, T. Wang, and X. Li, "Effects of microbiotic crusts on evaporation from the revegetated area in a Chinese desert," Australian Journal of Soil Research, vol. 45, no. 6, pp. 422-427, 2007.

[41] Z.-S. Zhang, L.-C. Liu, X.-R. Li, J.-G. Zhang, M.-Z. He, and H.-J. Tan, "Evaporation properties of a revegetated area of the Tengger Desert, North China," Journal of Arid Environments, vol. 72, no. 6, pp. 964-973, 2008.

[42] Y. Guo, H. Zhao, X. Zuo, S. Drake, and X. Zhao, "Biological soil crust development and its topsoil properties in the process of dune stabilization, Inner Mongolia, China," Environmental Geology, vol. 54, no. 3, pp. 653-662, 2008.

[43] S. Chamizo, Y. Cantón, I. Miralles, and F. Domingo, "Biological soil crust development affects physicochemical characteristics of soil surface in semiarid ecosystems," Soil Biology and Biochemistry, vol. 49, pp. 96-105, 2012.

[44] X. R. Li, D. S. Kong, H. J. Tan, and X. P. Wang, "Changes in soil and vegetation following stabilisation of dunes in the southeastern fringe of the Tengger Desert, China," Plant and Soil, vol. 300, no. 1-2, pp. 221-231, 2007.

[45] L. Deines, R. Rosentreter, D. J. Eldridge, and M. D. Serpe, "Germination and seedling establishment of two annual grasses on lichen-dominated biological soil crusts," Plant and Soil, vol. 295, no. 1-2, pp. 23-35, 2007.

[46] T. M. Langhans, C. Storm, and A. Schwabe, "Biological soil crusts and their microenvironment: impact on emergence, survival and establishment of seedlings," Flora, vol. 204, no. 2, pp. 157-168, 2009. 

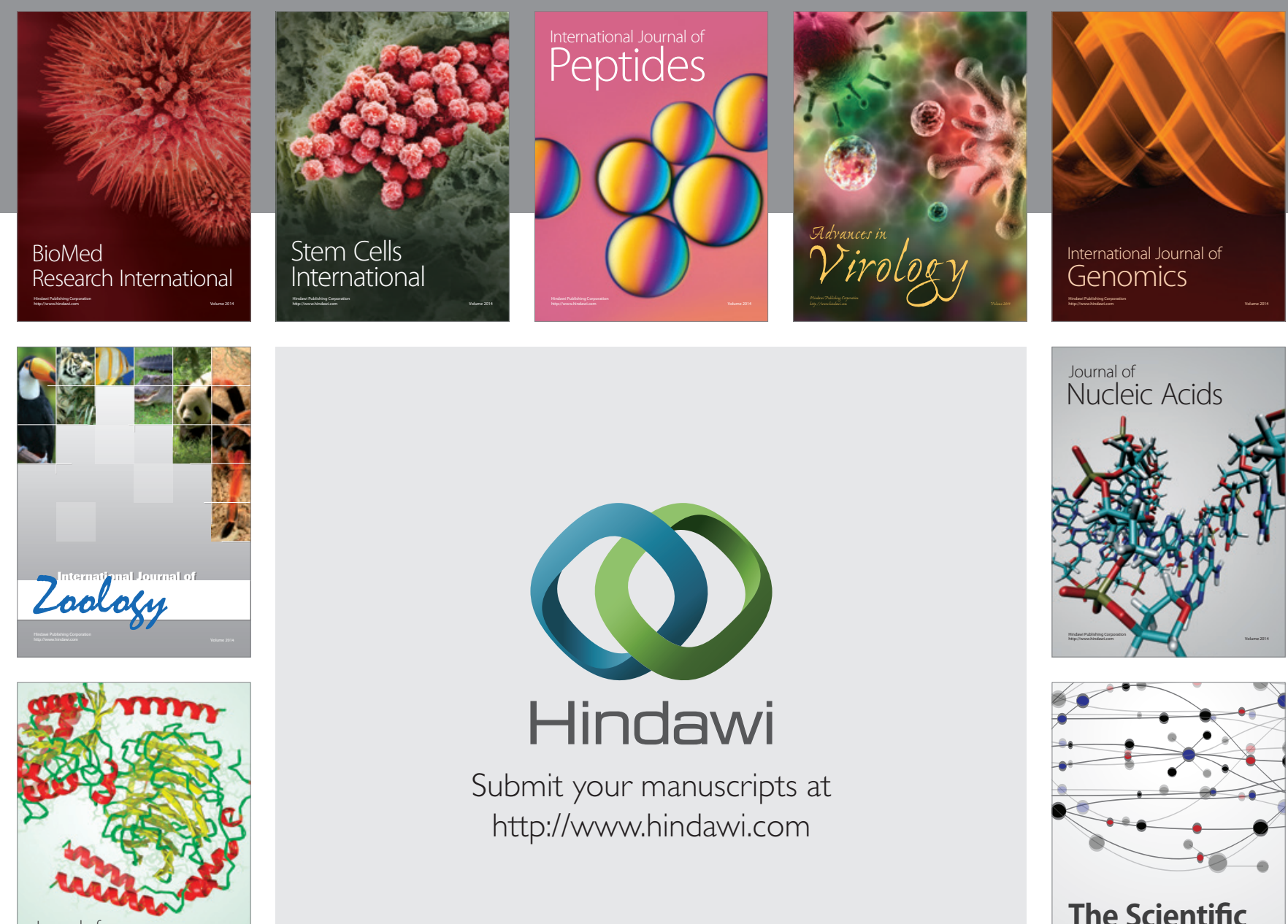

Submit your manuscripts at

http://www.hindawi.com

Journal of
Signal Transduction
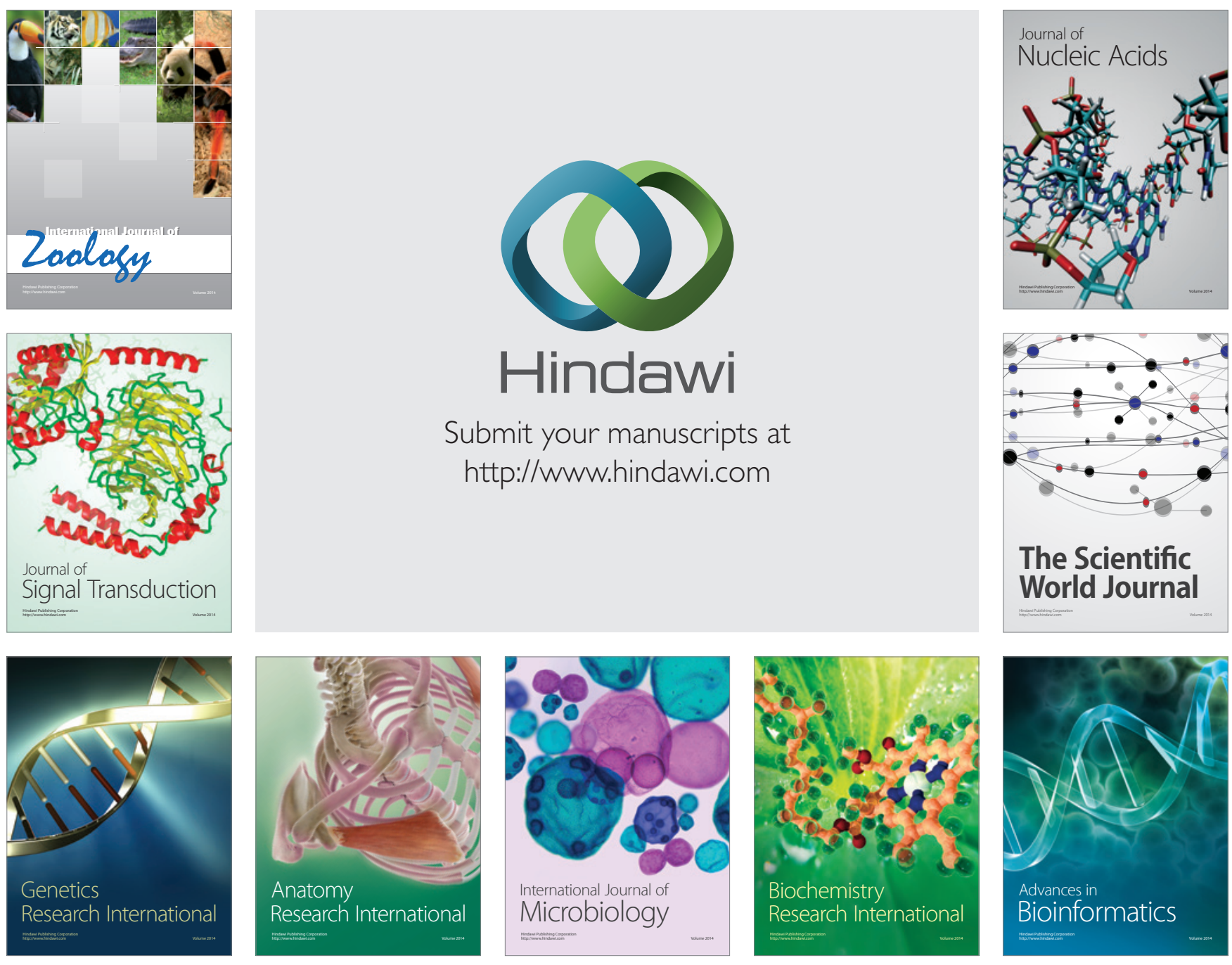

The Scientific World Journal
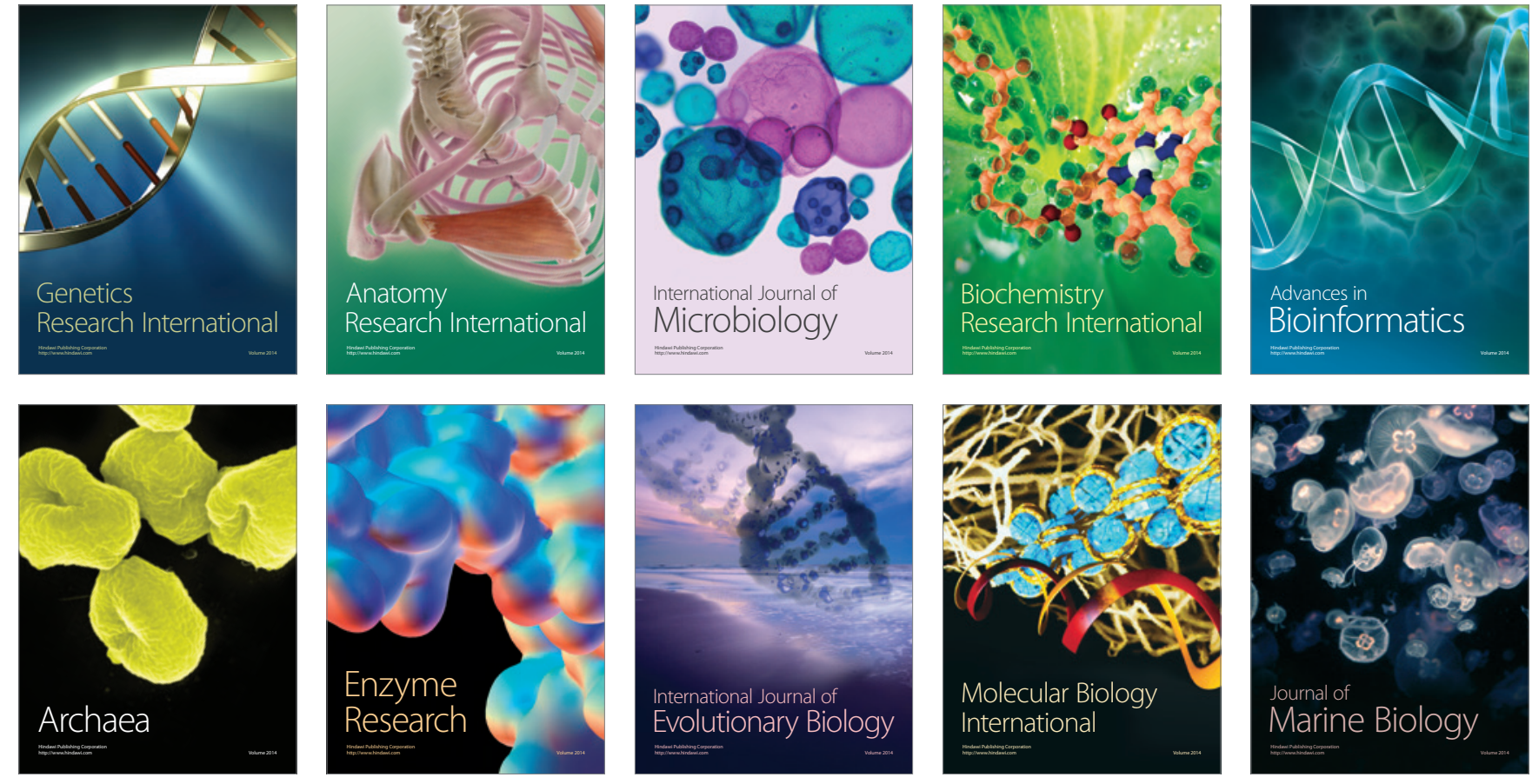